\title{
THE COVID-19 PANDEMIC: SOME ALTERNATIVE AND HOLISTIC ANTIVIRAL GIFTS OF NATURE
}

\author{
Kamal Asif \\ Head, Department of Geography, Delhi Public School (SW), Aligarh (U.P.), India \\ Email: kasif2006bustan@gmail.com
}

\begin{abstract}
This article unveils some of the nature's kindest gifts possessing properties in dealing with several viral infections. These are the substances obtained from living components of plants such as essential oils, gums, resins and other vegetative products. Such natural substances present in the plant bodies protect them against infections, heals physical injuries, provide resistance from disease and pests and other ill effects of the environment. Human beings use them in alternative methods of therapies with holistic approach in various kinds of ailments. At present, the entire world is in the shackles of the COVID-19 Pandemic leading to global socioeconomic lockdown. Till date, it is uneasy to say that, there is no proven solution to prevent and treat coronavirus disease rather to deal with the traditional complimentary therapies for various kinds of influenza, microbial infections and other common ailments. Thus, the main purpose of this article is to highlight the therapeutic importance and application of some commonly used herbal substances which may be helpful in preventing viral infections and safeguarding our homes from microbial advents, during this hard time of COVID-19 Pandemic.
\end{abstract}

Key words: Alternative Medicines, Therapeutic Herbs, Ayurveda, Unani and Naturopathy.

\section{Introduction}

Alternative and holistic systems of remedies is a complementary approach to health care and wellness which includes mental, emotional, functional, spiritual, social, and community aspects, and treating the whole person in a comprehensive manner. During the recent pandemic of COVID19, people around world are very much perceptive towards the alternative and holistic therapies. They include different modalities of naturopathy like steam inhalation, massage therapy, sauna baths, herbal tea and decoctions, fumigation etc. Throughout the human civilizations these alternative remedies with holistic approach of treatment are being successfully used. They have been used by human beings over the centuries in various ailments. Such methods can be very much helpful in curing viral infections and safeguarding our homes from microbial advents.

There are several therapeutic herbal products such as Frankincense, Myrrh, Lavender, Basil, Chamomile, Eucalyptus, Camphor, Benzoin, Sandalwood, Lemongrass, Bay leaves, Cinnamon bark, Licorice root, Tea Tree, Pine, and Geranium etc. Fumigation of living spaces by burning or vaporizing these natural substances is one of the oldest methods of holistic therapy. Ayurvedic fumigation with natural plant products is effective in reducing air-borne bacteria and in disinfecting inanimate surfaces. The traditional fumigation with herbal products has huge potential to address the problem of nasal infections. This method has been in practice since ages and proven by ancient cultures, religions and other communities. In the present day world, this kind of therapy has been outmoded due to modern lifestyle and insensitivity of new generation towards the roots. 


\section{Nature of the Virus}

According to Figueiras (2020), there are currently no proven studies on Novel Coronavirus; therefore we have to look to the influenza virus on the best way to deal with viral infections. Firstly, we need to consider that viruses have a lifecycle which can simply be explained in the following manner:

- entry into the host and binds with a cell in the respiratory tract (nose/throat/lungs)

- the surface proteins of the virus bind to receptors like a lock and key

- the virus is then able to enter the cell \& infect it

The virus must have a host to replicate. Viruses live longer on hard surfaces such as metal and plastic than they do on fabrics and soft surfaces. The virus may also be spread by airborne droplets which have landed and live in the environment waiting to be picked up and transferred to a live host. It can live on inanimate surfaces for potentially more than 24 hours (depending on the temperature \& humidity), but will eventually die without a host to infect. There are variety plant products such as essential oils gums, resins, barks and leaves etc. have been shown to disrupt the viral lifecycle at different stages.

Table 01: Common Ailments Associated with Coronavirus Disease and Effective Herbal Remedies

\begin{tabular}{|c|l|c|c|c|c|c|c|c|c|c|}
\hline S.No. & Herbal Plants & \multicolumn{7}{|c|}{ Common Ailments Associated with Coronavirus Disease } \\
\cline { 3 - 10 } & & $\begin{array}{c}\text { Throat } \\
\text { Infections }\end{array}$ & Sinusitis & Influenza & Bronchitis & $\begin{array}{c}\text { Common } \\
\text { Cold }\end{array}$ & $\begin{array}{c}\text { Joint } \\
\text { Pains }\end{array}$ & Insomnia & Depression & Anxiety \\
\hline 1. & Basil & - & - & $\square$ & $\square$ & $\square$ & $\square$ & - & $\square$ & $\square$ \\
\hline 2. & Eucalyptus & $\square$ & - & $\square$ & $\square$ & $\square$ & $\square$ & - & - & - \\
\hline 3. & Frankincense & $\square$ & - & $\square$ & - & $\square$ & $\square$ & $\square$ & $\square$ & $\square$ \\
\hline 4. & Geranium & $\square$ & - & - & - & $\square$ & $\square$ & $\square$ & $\square$ & $\square$ \\
\hline 5. & Lavender & $\square$ & $\square$ & $\square$ & $\square$ & $\square$ & $\square$ & $\square$ & $\square$ & $\square$ \\
\hline 6. & Lemongrass & $\square$ & $\square$ & - & - & - & $\square$ & $\square$ & $\square$ & - \\
\hline 7. & Licorice Root & $\square$ & $\square$ & - & $\square$ & $\square$ & $\square$ & - & - & - \\
\hline 8. & Pine & - & $\square$ & $\square$ & $\square$ & $\square$ & $\square$ & - & - & - \\
\hline 9. & Sandalwood & $\square$ & - & - & $\square$ & - & - & $\square$ & $\square$ & $\square$ \\
\hline 10. & Tea Tree & $\square$ & - & $\square$ & $\square$ & $\square$ & - & - & - & - \\
\hline
\end{tabular}

Source: Based on the knowledge from several literatures related to alternative and holistic systems of medicines.

\section{USE OF ALTERNATIVE AND HOLISTIC REMEDIES}

\section{Resins and Gums}

Aromatic antivirus resins are nature's own fragrant first-aid against viruses and bacteria (lyengar, 2020). Resins are extracted from the barks of a variety of tree species. One of the oldest is frankincense, a powerful remedy for the body and the soul. Frankincense is used in incense, natural medicines, perfumes, and essential oils that can be inhaled or applied to the skin for their purported health benefits. Frankincense and myrrh kill bacteria or any microorganisms including viruses as it was proven by the ancient Egyptians. Research about mummification by the ancient Egyptians reveals that the use of frankincense and myrrh was not just for the pleasant scent but to delay the decay process.

On a starlit night long ago, as the story goes, three wise men brought gifts to baby Jesus in a stable. One was gold, the others frankincense and myrrh (another sublime of resin) and has special mention in the Bible. Frankincense, was highly prized and thought to be worth its weight in gold, but it wouldn't have been hard to find. Trees that yield the fragrant resin were widespread in the lands of the Bible and beyond. This resin is obtained from several species of Boswellia tree which are typically grown in the dry-mountainous regions throughout northern Africa 
and in India, Oman, and Yemen, are increasingly under pressure, largely because of overexploitation for their aromatic resin (Fobar, R. 2019).

Oman is known as Al-Ard Al-Lubaan in Arabic which means 'the Land of Frankincense', that is mentioned in the Holy Quran. For more than 5000 years, Boswellia sacra tree in Oman's Dhofar region have been tapped for rare aromatic resin traded across Arabia, Africa, Europe, and Asia up to Far East, mostly known as Frankincense (or olibanum). This much sought after resin has been used for centuries in cultural ceremonies, as a cosmetic agent, and as traditional medicine to treat a variety of ailments like inflamed joints, congestion and anxiety (Environment Society of Oman). Frankincense is used in incense, natural medicines, perfumes, and essential oils that can be inhaled or applied to the skin for their purported health benefits (Fobar, R. 2019).

Figure 01: Production of Frankincense from Boswellia Tree, Fumigation and its Benefits

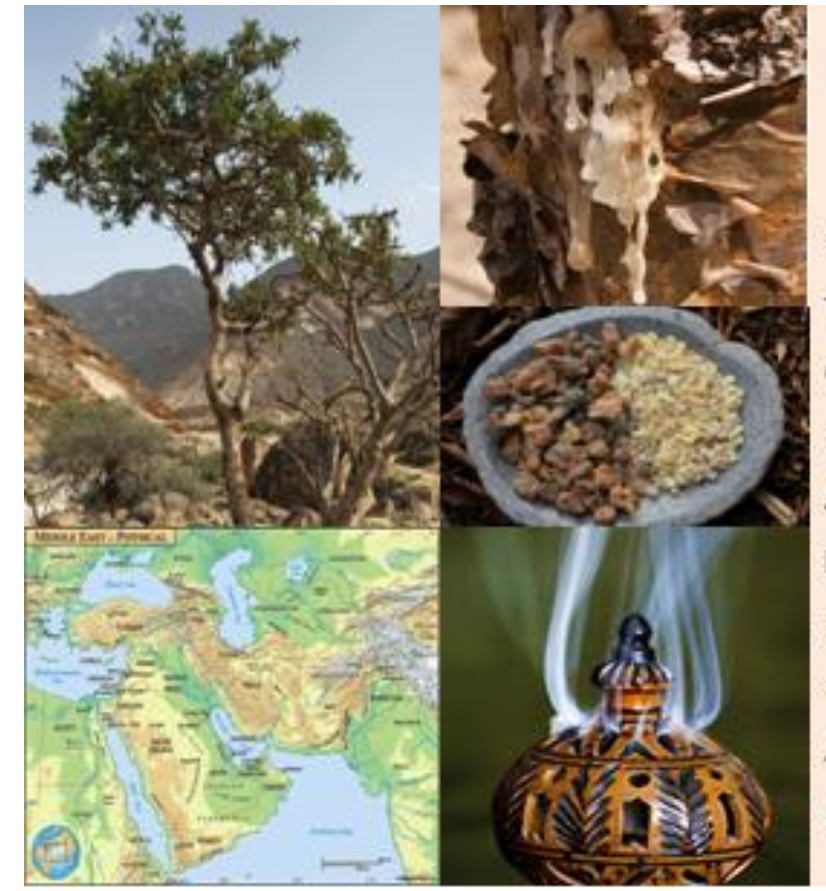

\section{HEALTH BENEFITS OF USING FRANKINCENSE (LOBAN)}

Boosting Physical and Mental Health

Throat Infections and Influenza

Creates Pleasant Atmosphere

Enhances Memory

Alleviate Anxiety

Improves Digestion

Kills Household Microbes

Reduce the Signs of Ageing

Anti-Inflammatory Properties

Strengthening the Immune System

Source: http://omantourismuk.blogspot.com/2015/11/; https://www.maps.com; https://www.healthline.com and https://www.ncbi.nlm.nih.gov

In the Islamic culture, the Holy Prophet Muhammad $(S)$ is reported to have said that, "incenses like Frankincense, Myrrh, Syrian Rue and Wormwood helps to expel evil spirits from the house". The Fourth Caliph of Islam Hazrat Ali (R.A) advised it best for enhancing memory, relaxing of respiratory system, proper kidney functioning and joint pains. Further, in the later Arabic medicines, frankincense has mentioned to heal bleeding wounds, stomach ache, weak indigestion, ulcers, diarrhea, flatulence, chest congestion, eyesight impairments etc.

In India, frankincense is commonly known as loban used as a fumigant to disinfect living spaces and as remedy in Ayurveda and Naturopathy. Boswellia trees are found in dry hilly areas of Rajasthan, Gujarat, Bundelkhand, Chattisgarh, Odisha, Telangana, and Karnataka. The burning of loban is more common in religious rituals because it is believed that it eliminates negative energies and allows positive energy to let. It is an antiseptic and disinfectant agent that has antimicrobial effects. It has the ability to eliminate cold and flu germs from the homes and the body naturally, and it can be used in place of chemical based household cleaners (Deo, 2020). Frankincense has a woody, spicy smell and can be inhaled, absorbed through the skin, steeped into a tea or taken as a supplement. Moreover, it is used in Ayurvedic and Unani system of medicines for hundreds of years, to offer certain health benefits, from improved arthritis and digestion to reduced asthma and 
better oral health. The other resins having antimicrobial properties found in India are Agar Wood, Acacia arabica (BabuI), Camphor, Pine, Deodar, Juniper, etc.

The future of frankincense is on risk because over exploitation and wrong methods of extraction form live trees and overgrazing by animal herders (Environment Society of Oman). Better attention of conservation practitioners, policy makers and frankincense companies, and improved management of frankincense forests may secure future production of this iconic resin (Teshome, M., et al. 2017). Thus, sustainable methods and awareness of conservation have to be inculcating among the local communities therein.

\section{Essential Oils}

Essential oils for their antiviral and relaxing properties have been used in all traditional systems of naturopathy. It is also known as aromatherapy because healing through fragrances. Healing of body through massages by using essential oils is one of the proven methods of stimulating blood circulation which in relieving anxiety, joint pains and depressions. Antiviral essential oils are an alternative form of treatment for some of the symptoms of colds and flu and can alleviate conditions like a blocked nose, or aid sleep to improve recovery times (Deo, 2020). There is a wide range of essential oils which can be used according to their healing properties. The most effective essential oils have been selected to present as herbal remedies for prevention of common ailments associated with Coronavirus (Table 01). They include Eucalyptus, Frankincense, Geranium, Lavender, Sandalwood, Tea Tree, Lemongrass etc. Among various essential oils, due to a high beneficial potential, frankincense oil is also referred as "the king of essential oils". It has healthboosting and beautifying effects, make frankincense essential oil as one of the favorites. It is a proven remedy for throat infections and influenza. Moreover, it has anti-inflammatory and antiageing effects, and enhances overall wellbeing by increasing efficiency of immune system (AYUSH).

The various methods of applications of these essential oils are masso therapy, steam inhalation, sauna baths, room sprays and vaporizers. For massage therapies concentrated essential oils are used blended with base oils like Almond, Walnut, Sesame, Coconut, Jojoba, Sunflower, etc. It depends on the availability and ideal weather conditions. These medicated oils used in the Ayurvedic system of medicine primarily used for local application in the treatment of skin disorders, bone and joint pain relief, relief from headache and hair and scalp problems.

Figure 02: Essential Oils for Aromatherapy and Herbal Decoctions

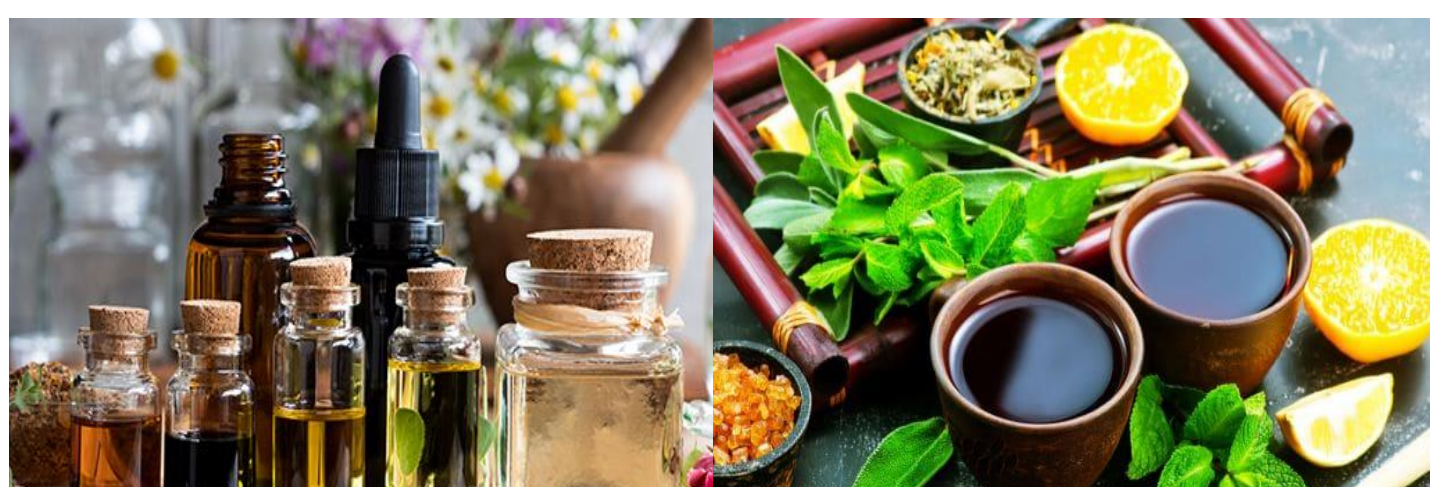

Image Courtesy: https://www.avpayurveda.com/ and https://food.ndtv.com/

\section{Herbal Decoctions}

Decoctions are the most commonly used traditional herbal preparations used in Ayurveda and Unani system of medicines. It is an oral medication that involves the extraction of the active components of herbal plants with boiling water, reduces it to half of its original quantity. Decoctions are normally prepared by using roots, stem wood, barks, gums, leaves, flowers, fruits and seeds of numerous medicinal plants. Some of the commonly used herbal products used for preparing herbal 
decoctions are obtained from Licorice Root (Mulethi), Ginger, Clove, Cinnamon, Black Pepper, Basil Leaves, Turmeric, Lemongrass, Mint leaves, Chamomile, Rosemary, Withinia (Ashwagandha), Ginseng, Jujube Fruit, Senna Leaves, Etc. During the procedure of preparing decoctions, the boiling utensil must be covered to prevent loss of any essential volatile component through evaporation. The final extract is strained using a filter, and used either as a whole or after suitable dilution in warm or hot water, as and when required. The therapeutic potential of herbal decoctions since ages has made it safe and effective in curing and preventing infectious diseases, common cold, cardiovascular ailments, inflammatory problems, body detoxification and blood purification. Decoctions are quiet a good to be used as immunity boosters among all ages.

\section{Misconceptions on Alternative and Holistic Remedies}

With no approved drugs for the Novel Coronavirus, people are turning to alternative medicines, often on the advice of their governments. Initially, the World Health Organization (WHO) had advised against taking traditional herbal remedies. But later it acknowledged that, some were turning to alternative medicines to alleviate some of the milder symptoms of COVID-19. Also the governments of some developing countries have claimed that combining herbal medicines with conventional medicine helped to deal with the outbreak. While there are other countries who are warning against the use of alternative herbal medicines and other therapies for treating COVID-19, on the ground of no evidence of cure and they are unsafe to use. However, China's National Health Commission issued a document claiming the recovery of COVID-19 patients by using several herbal medicines to relieve symptoms including weakness and fever, and a soup for clearing and detoxification of the lungs. The Ministry of AYUSH of the Government of India too has recommended the use of alternative herbal medicines and a dietary plan to strengthen the immune system. It was also clarified by the government that, it is an absolutely preventive measure rather than cure.

\section{Conclusion}

The present study concludes that, the alternative and holistic approaches of treatments of the body and the soul is an age old practice, since all human civilizations. The elements present in the plant products are self defensive agents against infections and diseases, and other environmental effects. A variety of plant substances like resins, gums, essential oils, bark, leaves, flowers, fruits and seeds are used as alternative remedies. Several plants and herbs are being used in different ailments in Ayurveda, Unani and Naturopathy. Frankincense (Loban) in the form of resin and essential oil has proven effects on bacterial and other viral infections, and checks microbial advent in our living spaces. Besides these effects, it is also used as a remedy in other common ailments. Moreover, this natural substance has powerful actions against negative energies which are also accepted in various cultures and religions. Thus, the usage of frankincense makes our living spaces pure and full of positivity to live a healthy life. In the current situation of COVID-19 Pandemic, such remedies can be very effective as a preventive measure against common symptoms like influenza, throat infections, common cold, insomnia and anxiety. They are also helpful in safeguarding our homes from the advent of airborne viral infections and other microbes. However it is to be noted that, these therapeutic approaches of alternative and holistic medicines are not intended for any treatment, as they are complimentary and preventive in nature.

\section{References}

1. Arya Vaidya Pharmacy (2020) https://www.avpayurveda.com/

2. Bhatwalkar, S.B. at el. (2019) Validation of Environmental Disinfection Efficiency of Traditional Ayurvedic Fumigation Practices. Journal of Ayurveda and Integrative Medicine, Elsevier, JulySept., Vol. 10, No. 3, pp. 203-206. 
3. Environment Society of Oman. www.eso.org.om/index/images/file/201603/PosterEnglish_Hires_.jpg

4. Featured Health Topics (2020). https://www.healthline.com/nutrition/13-anti-inflammatoryfoods.

5. Figueiras, S. (2020). Novel Coronavirus Aromatherapy Guide: Essential Oils Dos \& Don'ts. The original article by clinical aroma therapist Emma Ross was originally posted on the Facebook Living Well in Hong Kong, co-founded by yoga therapist Charlotte Douglas and wellness enthusiast Susan Duffy.

6. Fobar, R. (2019). Frankincense trees-of Biblical Lore-are being tapped out for Essential Oils: The Fragrant Resin Gifted to the Newborn Jesus may be at Risk of Disappearing, National Geographic Wild watch, December 13, 2019.

7. lyengar, K. (2020) Read more at: https://www.deccanherald.com/living/living-front page/aromatic-antivirus-815746.html

8. Kuete, V. (2017). Medicinal Spices and Vegetables from Africa. Elsevier. p.694.

9. Los Angeles Times (2020). To Fight the Coronavirus, Some Patients Turn to Alternative Medicine. Article published by Associated Press, $17^{\text {th }}$ April, 2020, New York.

10. McGilvery, C., Reed, J. and Mehta, M. (2003). Practical Handbook of Massage, Aromatherapy and Yoga. Anness Publishing Ltd. London, p.256.

11. Ministry of AYUSH, Government of India, https://www.ayush.gov.in

12. National Center for Complementary and Integrative Health (NCCIH) https://nccih.nih.gov/

13. NDTV (2020) Herbal Remedies https://food.ndtv.com/

14. Teshome, M., et al. (2017). Uniquely Regenerating Frankincense Tree Populations in Western Ethiopia. Forest Ecology and Management, Vol. 389, No.1, pp. 127-135.

15. World Health Organization (WHO). https://www.who.int/iris

16. https://www.ncbi.nlm.nih.gov/pubmed. 